\title{
A PULSÃO DE MORTE E A GÊNESE DA ANGÚSTIA
}

Lara Cristina d'Avila Lourenço

Doutora em Psicologia (USP); mestre em Filosofia e Metodologia das Ciências (UFSCar); professora adjunta da Universidade Federal de São Paulo (Unifesp).
RESUMO: Com base na tese sobre a angústia somática, a qual assume que o substrato da angústia é a tensão sexual excessiva e desligada, apresenta-se a hipótese de que a ação da pulsão de morte sobre a pulsão de vida produz uma forma primordial de angústia. Essa angústia ainda não se caracterizaria como sensação, mas como pura quantidade que, com o desenvolvimento do aparelho psíquico, seria utilizada pelo ego para defesa. Portanto, a prontidão angustiada (Angstbereitschaft), descrita em Além do princípio do prazer, teria como fundamento tal forma de angústia.

Palavras-chave: Angústia; pulsão; trauma.

ABSTRACT: The death impulse and the genesis of anguish. Based in the thesis about somatic anguish, which declares that the substratum of anguish are extreme sexual tension and extreme sexual off, this article presents the hypothesis that the action of death impulse around of life impulse produces a primordial form of anguish. This anguish is not yet characterized as sensation, but as pure amount that, with the development of the psychic apparatus, would be used by the ego for the defense. Therefore, the readiness for anguish (Angstbereitschaft), described in Beyond the principle of the pleasure, would have as bedding such form of anguish.

Keywords: Anguish; impulse; trauma.

\section{INTRODUÇÃO}

Abordamos os textos freudianos iniciais (FREUD, 1894a [1950]/1980 e 1894b[1950]/1980) para encontrar as explicações sobre a angústia, a qual estaria na gênese da então denominada "neurose de angústia". Assim, os determinantes dessa angústia estariam na esfera somática, ou, para resumir, na tensão sexual acumulada que não alcançou as ligações psíquicas, exigidas para a formação da libido e descarga adequada. Essa angústia primeira e somática poderia, mais tarde, ser utilizada para fins de defesa. Melhor dizendo, Freud conclui que a angústia neurótica poderia vir a ser angústia histérica. Essa 
afirmação segue com a interessante tese de que a neurose de angústia constitui o substrato somático da histeria (FREUD, 1894b[1950]/1980, p.111).

A partir dessas ideias, chegamos a Além do princípio do prazer (FREUD, 1920/1980) para supor, do mesmo modo, que a gênese da angústia é anterior ao domínio psíquico. E ainda, nossa suposição entende que essa forma primordial de angústia, que seria causada pela ação da pulsão de morte sobre a pulsão de vida, está nas bases do domínio psíquico, na medida em que seria uma quantidade da qual o ego se utilizaria para ficar em prontidão e assim ligar os estímulos.

Com efeito, ao efetuarmos essa hipótese, não julgamos que a angústia, descrita nos quadros de neurose de angústia, seja a mesma que concebemos a partir de Além do princípio do prazer (FREUD, 1920/1980). Lançamos mão apenas das concepções iniciais de Freud, para propormos uma possível leitura da angústia, já sob a égide do dualismo pulsional estabelecido em 1920. Sem dúvida, essa interpretação acredita na continuidade do pensamento freudiano sem, contudo, negar seus movimentos (MONZANI, 1989).

Em nossa leitura de Além do princípio do prazer (FREUD, 1920/1980), encontramos a angústia ${ }^{1}$ como substrato inerente ao início dos fenômenos vitais. Especificamente, entendemos que a ação concorrente, entre as pulsões ${ }^{2}$ de morte e de vida, produz uma forma primordial de angústia. Talvez fosse melhor dizer que, segundo tal leitura, o substrato da angústia é uma consequência lógica desse funcionamento pulsional.

Nessa obra (FREUD, 1920/1980), o início da vida é concebido como reação à estimulação externa. A matéria, de início inorgânica, teria sido animada pelos estímulos externos e, como consequência imediata, ela buscaria descarregar tal tensão. Entretanto, essa descarga não se dá de forma direta. Conforme aumentam as complexidades dos estímulos, o caminho para a descarga é mais tortuoso. E para percorrê-lo, os estímulos devem estar submetidos a um domínio, isto é, a

\footnotetext{
${ }^{1}$ A edição Standard brasileira das obras completas de Sigmund Freud (1980) com frequência traduz o termo Angst por ansiedade, com a seguinte justificativa: "Preferimos usar 'ansiedade' para nos referir à vivência do sofrimento psíquico determinado pela presença de um conflito interno. Designa, pois, predominantemente, o aspecto mental do fenômeno e se aproxima certamente mais da abordagem metapsicológica" (Nota do tradutor brasileiro, FREUD, 1917/1980, p.457). Assim, somente nos primeiros textos freudianos, essa edição adota o termo angústia, uma vez que eles enfatizam o papel somático de Angst. Em nosso trabalho, consideramos que Angst tem sempre um substrato somático e envolve reações de descargas fisiológicas. Dessa maneira, não vemos sentido em substituir o termo angústia por ansiedade, na tradução de Angst. Utilizamos o termo angústia no decorrer de todo o texto; inclusive nas citações mantemos esse termo, quando na referida edição se lê ansiedade.

2 Também em relação ao termo Trieb, tomamos a liberdade de modificar os textos da Edição standard brasileira das obras completas de Sigmund Freud (1980), na qual está esse termo alemão traduzido por instinto. Observando que Freud, muitas vezes, faz questão de enfatizar as diferenças entre Trieb e Instinkt, adotamos o termo pulsão onde se lê instinto, na edição citada.
} 
um processo de ligação (Bindung) às representações psíquicas. Cumpre ressaltar que tal processo é, segundo Freud, a operação primordial do aparelho psíquico. Em 1920, Freud afirma que, somente após certo grau de ligação, é que tal energia pode ser descarregada e o prazer, identificado nessa descarga, pode ser experimentado e estabelecido como princípio. A falha nesse processo de ligação desencadeia a compulsão à repetição que, por sua vez, é justamente o mecanismo que indica a Freud os dados para nomear a pulsão de morte.

Os vetores da pulsão de morte levam à descarga total e imediata dos estímulos; enquanto outro conjunto de pulsões atua na direção das ligações psíquicas, exigidas para a sustentação da vida. Isto é, esse conjunto de pulsões busca impedir que o organismo morra antes do tempo. Por isso tais pulsões, nas quais Freud inclusive encontra a força da sexualidade, são agora denominadas "pulsões de vida".

A ação das pulsões de morte e de vida, embora não contraditória (entendemos que não é contraditória, porquanto ambas as pulsões têm como fim a descarga dos estímulos) é concorrente: as primeiras mantêm ou mesmo provocam o desligamento da energia; às segundas interessam as ligações psíquicas. E nossa hipótese é a de que, no encontro entre tais pulsões, produz-se o estado original da angústia. Isso porque, baseando-nos nos critérios sobre a angústia somática (FREUD, 1894b[1950]/1980), pensamos que a energia excessiva e desligada, que assim se apresenta, pode ser considerada uma forma primordial da angústia, ou seja, o substrato primeiro desse afeto. Para o desenvolvimento de nosso texto, denominamos tal substrato de "angústia quantidade".

É óbvio que não se trata da angústia sinalizadora de perigos (Angstbereitschaft), que Freud (1920/1980) enfatiza no texto. Pois essa sinalização funciona por meio do acionamento do princípio de prazer, o qual já é resultado do citado processo de ligação. Trata-se de uma produção anterior, referente ao estabelecimento da angústia enquanto quantidade, que seria delimitada enquanto um traço de memória. Nesse ponto, esclarecemos que, com o termo "traço de memória”, referimo-nos a uma espécie de percurso privilegiado pelo organismo, estabelecido em virtude da relação entre investimento e descarga da excitação. Sem dúvida, essa explicação remonta às teses de Projeto para uma psicologia científica (FREUD, 1895a[1950]/1980), embora elas não se utilizem de tal expressão (uso só realizado em Interpretação dos sonhos [FREUD, 1900/1980]).

O alcance dessa angústia quantidade como sensação, ou melhor, como algo que pode ser percebido, só é possível na medida que há um mínimo de desenvolvimento do aparelho psíquico, com efeito, quando o ego já pode interferir no curso das quantidades, utilizando-as para propósitos de defesa.

Dessa maneira localizamos, em Além do princípio do prazer (FREUD, 1920/1980), duas formas de angústia: a primeira seria pura quantidade, utilizada como 
substrato para o desenvolvimento da segunda, a qual se apresentaria como sensação. Assim, falamos em angústia quantidade e "angústia sensação" (ou seja, como inerente à função egoica de percepção). Interessa apontar que, de início, identificamos a primeira forma da angústia com o que Freud (idem) distingue como "susto". Todavia, acabamos adotando a ideia de que o susto provavelmente refere-se à reação psíquica imediata à alta energia desligada, enquanto a angústia quantidade, de alguma maneira, coincidiria com a própria energia traumática e seus caminhos somáticos. Talvez seja mais correto afirmar que isso que denominamos angústia quantidade seja equivalente ao que Freud, em Inibições, sintomas e angústia (1926/1980), compreende como “angústia automática”. Contudo, não deixa de ser interessante notar que, segundo esse texto (idem), o protótipo da angústia automática está na situação do nascimento. Já a angústia, que supomos no encontro pulsional, estaria numa ordem metapsicológica, não sendo localizada numa situação temporal específica.

Esperamos que nossa hipótese seja justificada, conforme inserida no raciocínio do texto de Freud (1920/1980). Sem dúvida trata-se de uma hipótese lógica, consequente à teoria sobre as pulsões. Cientes das dificuldades inerentes às suposições sobre os processos anteriores à formação do ego, não temos a pretensão de que a hipótese deste artigo esteja isenta de controvérsias e ambiguidades. Apenas pretendemos apresentar uma possível leitura dos aspectos metapsicológicos da angústia, no processo de constituição psíquica.

\section{CONCEITO DE ANGÚSTIA SOMÁTICA}

Ainda nos Estudos sobre a histeria (BREUER e FREUD, 1893 [1895]/1980), as vivências traumáticas externas começam a se mostrar insuficientes para explicar a manutenção ou surgimento da angústia. Dessa maneira, Freud (1894a[1950]/1980) inicia o estudo sobre uma fonte interna, anterior às defesas psíquicas, que justifique essa sintomatologia. O autor postula, então, bases orgânicas na gênese da angústia. E conclui que, uma vez formada, a angústia pode aparecer como reação às cenas traumáticas e ser depois repetida histericamente. Dessa forma, há uma angústia somática e outra psíquica, sendo a relação entre ambas não de exclusão, mas de complementaridade: a primeira justifica a forma e manutenção da segunda. Isto é, o substrato da angústia é sempre somático, o que pode ser somático ou psíquico é o fator que a desencadeia.

No Rascunho E (FREUD, 1894a[1950]/1980), para apresentar o conceito de angústia somática o autor comenta suas observações sobre a relação entre angústia e vida sexual. Ele diz que interpretava a angústia, despertada na situação de coito interrompido, como um sintoma histérico. Esse raciocínio obedecia ao modo de conceber o afeto intimamente relacionado às situações externas: durante o coito seriam considerados os perigos reais de gravidez, que condicio- 
nariam o sentimento de angústia, o qual seria repetido histericamente em outras situações. Porém, diante da contingência do temor de gravidez, Freud conclui que a angústia, ligada ao coito interrompido, não é necessariamente a repetição de um afeto causado por um perigo externo. "Assim, a angústia da neurose de angústia não era continuada, relembrada, histérica” (FREUD, 1894a[1950]/1980, p.212, grifo do autor). E ainda observa que a mesma angústia neurótica é encontrada em sujeitos psiquicamente diferentes em suas reações ao ato sexual. Com isso, o autor afasta a gênese da angústia da esfera psíquica: “Esse aspecto é interessante, e só pode significar que a origem da angústia não deve ser buscada na esfera psíquica. Por conseguinte, deve estar radicada na esfera física: é um fator físico da vida sexual que produz angústia” (idem).

Na heterogeneidade de condutas de abstinência sexual (virgindade, voluntária ou não; coito interrompido; impotência), Freud (1894a/[1950]/1980, p.216) encontra o fator físico causador da angústia. Trata-se de uma acumulação de tensão sexual física que, impedida de ser descarregada, transforma-se em angústia.

As explicações para tal transformação podem ser buscadas nas teses do princípio de constância. Segundo tal princípio, a excitação exógena que atinge o organismo é eliminada por uma ação de igual magnitude. Entretanto, as excitações internas não podem ser eliminadas da mesma forma direta. Para serem descarregadas, tais excitações devem se acumular até alcançarem um limiar, a partir do qual entram em contato com grupos de representações psíquicas, que podem organizar uma ação específica de descarga. Há casos, porém, em que o acúmulo da tensão sexual interna não estabelece a junção com as representações psíquicas. Isso impede, portanto, a descarga adequada da excitação. Nesses casos, a descarga possível permanece na esfera somática, por meio das reações de angústia.

Essas considerações implicam no fato de que a sexualidade possui uma complementaridade entre componentes físicos e psíquicos. É nessa junção que se concebe o conceito de libido, ou afeto sexual. Logo, é a tensão sexual que pode produzir tanto angústia quanto libido, conforme ela se una ou não às representações psíquicas (CANEPPELE, 1996). Vale observar que tal raciocínio é distinto da tese freudiana, de acordo com a qual a angústia é resultado de uma transformação da libido (tese que pode ser considerada a síntese principal das primeiras teorizações sobre a angústia, na obra do autor [FREUD, 1915/1980]).

Dessa forma, a angústia consiste num produto da tensão sexual física, que não alcançou o estatuto de afeto sexual (libido), o qual implica na conexão das tensões somáticas com as representações psíquicas. Esse processo e suas possíveis causas são resumidos na seguinte afirmação:

“Nos casos em que há um considerável desenvolvimento da tensão sexual física, mas esta não pode ser convertida em afeto pela transformação psíquica — por 
causa do desenvolvimento insuficiente da sexualidade psíquica, ou por causa da tentativa de suprimi-la (defesa), ou por causa do declínio da mesma, ou por causa do alheamento habitual entre sexualidade física e psíquica —, a tensão sexual se transforma em angústia. Assim, nisso desempenham um papel a acumulação de tensão física e a evitação da descarga no sentido psíquico.” (FREUD, 1894a[1950]/1980, p.216, grifo do autor)

Mas por que essa tensão sexual física se transforma precisamente em angústia? As características principais da angústia (taquicardia, dispneia) seguem, basicamente, duas estruturas biológicas: o estímulo da respiração (que não permite elaboração psíquica) e as vias subcorticais do coito (o qual seria a descarga adequada para a tensão). Isso permite a hipótese de que a formação da angústia segue caminhos facilitados pelo organismo.

A relação entre a excitação sexual somática e as representações psíquicas, na etiologia das neuroses, continua a ser descrita no Rascunho G. Nele, Freud (1895b [1950]/1980) compara os mecanismos subjacentes à melancolia e à angústia. Na melancolia, há um empobrecimento da excitação somática, o qual, por sua vez, causa uma inibição, uma espécie de retração dos conteúdos psíquicos. Assim, nesse quadro, também se constata o não-funcionamento da engrenagem entre a tensão sexual somática e os representantes psíquicos. É muito interessante notar que, nesse manuscrito, o autor adota a importante tese, que é enfatizada em Projeto para uma psicologia científica (FREUD, 1895a [1950]/1980), de que a quebra das associações psíquicas produz sofrimento:

"Podemos imaginar que, quando o ps. G [grupo sexual psíquico] se defronta com uma grande perda da quantidade de sua excitação, pode acontecer uma retração para dentro (por assim dizer) na esfera psíquica, que produz um efeito de sucção sobre as quantidades de excitação contíguas. Os neurônios associados são obrigados a desfazer-se de sua excitação, o que produz sofrimento. Desfazer associações é sempre doloroso." (FREUD, 1895b[1950]/1980, p.227, grifo do autor)

As ideias sobre a angústia somática são sintetizadas no artigo dedicado à descrição da neurose de angústia, Sobre os critérios para destacar da neurastenia uma síndrome específica denominada 'neurose de angústia' (1894b/1980). Aqui, o autor consegue focalizar a etiologia somática dessa neurose, sem confundi-la com os determinantes da neurastenia. Embora ambas as afecções sejam baseadas em fatores sexuais somáticos, elas são distintas: na neurastenia genuína, a descarga adequada da tensão sexual é substituída por uma inadequada (por exemplo, a masturbação); na neurose de angústia, a excitação sexual somática não é elaborada psiquicamente. Enquanto naquela há um empobrecimento da tensão sexual (na medida que há 
descarga, embora inadequada), nessa há acúmulo dessa tensão, cuja vicissitude é a angústia somática.

Apesar do título, esse artigo não enfatiza tanto a distinção entre neurastenia e neurose de angústia, quanto à distinção entre as neuroses psíquicas (também denominadas neuroses de defesa ou psiconeuroses) e as neuroses sexuais (em outros termos, neuroses atuais, entre as quais se encontram a neurastenia e a neurose de angústia). E reafirma a etiologia da neurose de angústia nas características da vida sexual do paciente (excluindo daí apenas os casos em que há tara hereditária), particularmente nas situações de abstinência e coito interrompido. Tais causas, se não são suficientes para desencadear a neurose, pelo menos predispõem o indivíduo a adquiri-la.

Uma última observação, sobre a gênese da neurose de angústia, refere-se aos casos em que o indivíduo esteve exposto a uma sobrecarga de trabalho (por exemplo, cuidando de um enfermo). Como enquadrá-los nos efeitos do coito interrompido? Freud (1894b[1950]/1980) responde que, nesses casos, se a libido é pouco resistente, com o cansaço ela é subvertida a tal medida que não pode mais lidar com a excitação somática, a qual torna-se, portanto, desligada das representações psíquicas.

Desse modo, segundo as palavras do autor, vê-se em todos os casos de neurose de angústia um mecanismo sexual somático. Em outros termos, trata-se de um desvio, de uma impossibilidade no processo de formação da libido, a partir da tensão sexual. E por que isso ocorre? A resposta está nas disfunções da relação entre o psíquico e o somático: os representantes psíquicos podem não ser suficientemente desenvolvidos, ou pode haver uma alienação entre as esferas psíquicas e somáticas (alienação que pode ser causada por uma repressão intencional das representações sexuais).

Nas neuroses de defesa, também há mecanismo sexual somático e disfunção no uso das representações psíquicas. Isto é, tanto em um quanto em outro tipo de neurose, encontra-se acúmulo de tensão sexual e insuficiência psíquica, que levam às descargas somáticas inadequadas. Porém, a neurose de angústia relaciona-se com uma excitação sexual que não chegou a atingir o psiquismo. Já a neurose de defesa refere-se a uma tensão sexual que recebeu alguma elaboração psíquica, sendo mais tarde alvo de um conflito.

Os aspectos comuns à etiologia das neuroses de defesa e à etiologia da neurose de angústia evidenciam-se numa sintomatologia, em muitos pontos, equivalente. O quadro clínico da neurose de angústia apresenta: irritabilidade geral (o que aponta para o acúmulo de excitação); expectativa angustiada; despertar em pânico durante a noite; vertigens; ataques de angústia. Freud constata (1894b[1950]/1980) que tais não estão ausentes nos casos de histeria. Ao contrário, eles parecem estar na base mesma dos fenômenos histéricos. Esse fato 
começa a dificultar a distinção tão nítida entre as duas formas de neurose. E o enfraquecimento da fronteira entre histeria e neurose de angústia recebe duas soluções: o diagnóstico de neurose mista, e a interessante tese de que a neurose de angústia constitui o substrato somático da histeria (FREUD, 1895b/1980).

\section{A NOÇÃO DE TRAUMA E A FUNÇÃO DA ANGÚSTIA}

Em Além do princípio do prazer, Freud (1920/1980) parte da noção de trauma para analisar as razões da angústia. Nessa obra, o trauma é apresentado conforme as premissas de Projeto para uma psicologia científica (FREUD, 1895a[1950]/1980), as quais descrevem a situação do organismo exposto às excitações internas e externas. Em 1895, o autor afirma a existência de telas de proteção que filtram os estímulos externos, tornando-os suportáveis para o organismo; e que os estímulos internos, naturalmente reduzidos em comparação aos externos, atuam direta e ininterruptamente sobre o aparelho psíquico. Além do princípio do prazer (idem) segue o mesmo raciocínio, através da noção de escudo protetor contra estímulos.

Somente sob essa proteção, fracionados, é que os estímulos podem ser experimentados. E o espaço de experimentação deles é justamente abaixo do escudo protetor, no córtex sensitivo, que é o órgão diferenciado para a recepção de estímulos e onde Freud (1920/1980) localiza a consciência e a pré-consciência. Esse órgão recebe estimulação de origem tanto interna quanto externa, mas apenas em relação à primeira existe a atuação do escudo protetor; os estímulos internos atuam diretamente sobre o córtex sensitivo.

Quantidades excessivas de estímulos podem ocasionar o rompimento do escudo protetor, caracterizando o trauma. Mas convém notar que essa explicação é clara no que concerne aos estímulos externos. Quanto à tensão interna, como se daria o trauma, uma vez que ela não está submetida ao escudo protetor? Segundo Freud (1920/1980), quando as tensões endógenas aumentam em demasia, a única forma de defesa do aparelho psíquico é tratá-las como se fossem externas (o que fundamentaria o mecanismo de projeção). Dessa forma, haveria a possibilidade de atuação do escudo protetor.

Contudo, parece-nos que essa ideia é um tanto confusa. Afinal, esse escudo parece ser descrito em termos materiais na periferia externa do organismo. Sendo assim, como conceber que um mecanismo de projeção psíquica possa submeter os estímulos endógenos a esse escudo de proteção? E ainda, como imaginar que tais estímulos sejam projetados antes mesmo de sua atuação traumática sobre o córtex sensitivo (o qual Freud [1920/1980] parece identificar com o próprio aparelho psíquico?).

Nesse ponto tocamos na obscura ideia de espacialização psíquica. Embora Freud refira-se a lugares psíquicos sem estabelecê-los numa localização precisa, ele insiste na separação entre interno e externo. O organismo, descrito em Além 
do princípio do prazer (FREUD, 1920/1980), tem o córtex sensitivo como eixo central, na fronteira entre os meios externo e interno. Dessa forma, ele recebe estímulos de ambos os pólos. Entretanto, são os estímulos provenientes do mundo externo que o ocupam mais e são sinalizados pela consciência. Pois, segundo Freud, os estímulos externos criam uma espécie de facilitação na camada externa do córtex. Já as tensões internas não têm uma forma de impacto própria; elas têm como modelo a forma de atuação dos estímulos externos. Mas como isso é possível? A resposta não pode ser conclusiva, em virtude da ambiguidade com que Freud refere-se aos limites externo e interno. Embora o autor mantenha a ideia de que o córtex sensitivo é o ponto central, ora esses limites parecem dizer respeito ao aparelho psíquico, ora ao ego. Sendo assim, pode ser que um estímulo seja externo ao ego, mas interno ao aparelho psíquico.

Considerando essa ambiguidade, indicamos o que é afirmado sobre os limites do ego, em O ego e o id (FREUD, 1923/1980). Essa obra, enfatizando o estreito vínculo entre o corpo e o ego, devido ao papel da percepção para ambos, traz a estranha noção de que o ego é uma superfície oriunda do interior: “O ego é, primeiro e acima de tudo, um ego corporal; não é simplesmente entidade de superfície, mas é, ele próprio, a projeção de uma superfície” (FREUD, 1923/1980, p.40). Laplanche (1998) vê nessas palavras de Freud a ideia de que o ego é uma espécie de corpo interno, tangencial ao biológico, que é projetado para a recepção dos estímulos externos. O ego é um corpo interno que atua como superfície tanto para os estímulos internos quanto para os estímulos externos. Dessa maneira, mesmo os estímulos internos são recebidos como oriundos do outro lado da fronteira do ego. Isso demonstra que a localização psíquica, postulada por Freud, não se confunde com a topografia neuronal.

Sem procedermos à análise desse complexo assunto da teoria freudiana, que é a noção de periferia interna, notamos que o alvo de Freud é enfatizar que o excesso de estímulos, internos ou externos, causa o prejuízo das funções egoicas.

Para explicar o trauma envolvido na invasão excessiva de estímulos, Freud (1920/1980) toma como modelo o sofrimento físico. Na dor física, há a efração de uma área histológica limitada, através da qual passa um fluxo contínuo de excitações desde a periferia externa até o interior do corpo. A reação da mente a isso, segundo o autor, é catexizar a área de ruptura numa tentativa de cicatrizá-la. A dor ocorre justamente no encontro entre a energia invasora e a libido narcísica, a qual é responsável por essa reação que tenta imobilizar a invasão. Esse pensamento, como bem alerta Monzani (1989), esclarece que a dor tem um caráter diferente daquele do desprazer. A dor não está no aumento de tensão, mas no processo de ligação psíquica que decorre da invasão excessiva de estímulos.

Da dor física, Freud (1926/1980) deduz a explicação da dor psíquica. Em ambos os casos, há a inundação de energia em virtude de uma ruptura. Na si- 
tuação da dor psíquica, a ruptura é entre a libido e o objeto. A energia livre, que assim avança, choca-se com a tentativa de ligação que, aqui, acontece por meio de uma intensa catexia do objeto ansiado. Dessa dedução, Freud ratifica a ideia de que a dor se define no processo de ligação, que tem como objetivo restaurar a continuidade das excitações:

\begin{abstract}
"Penso ser aqui que encontraremos o ponto de analogia que tornou possível levar as sensações de dor até a esfera mental, pois a intensa catexia de anseio que está concentrada no objeto do qual se sente falta ou que está perdido (uma catexia que aumenta com firmeza porque não pode ser apaziguada) cria as mesmas condições econômicas que são criadas pela catexia da dor que se acha concentrada na parte danificada do corpo. Assim, o fato da causação periférica da dor física pode ser deixado de lado. A transição da dor física para a mental corresponde a uma mudança da catexia narcísica para a catexia de objeto." (FREUD, 1926/1980, p. 197, grifo nosso)
\end{abstract}

De acordo com essa citação, não há a necessidade de recorrer à ideia de efração das barreiras do ego, a partir da periferia interna, para justificar a dor psíquica. No entanto, vale comentar que é dessa ideia que Laplanche (1998) se serve. Esse autor explica que as pulsões são oriundas do interno, mas que atacam o ego desde o exterior. Logo, para ele, na dor física e na dor psíquica tratar-se-ia de dois invólucros diferentes: o invólucro do corpo e o invólucro do ego, respectivamente.

$\mathrm{Na}$ distinção entre a dor física e o trauma físico, existe apenas a diferença de extensão: no caso da dor, a efração atinge uma área limitada; no trauma físico, a área lesionada é ampla. E das condições do trauma físico, Freud (1920/1980) conclui a etiologia do trauma psíquico, especificamente, da neurose traumática. Nesse ponto, o autor consegue adicionar valor psíquico ao choque mecânico. Ou seja, na base do trauma psíquico, tal qual na do trauma físico, está o choque mecânico. A consequência psíquica do choque ocorre porque ele desencadeia uma excitação sexual, para a qual o aparelho psíquico não estava preparado.

O principal determinante da neurose traumática é o fato de o aparelho psíquico ser surpreendido pelo afluxo de energia sexual. Se esse aparelho não é tomado de susto, mas está prevenido para o excesso de estímulos, ele pode dominá-lo psiquicamente, transformando a energia livremente móvel em energia ligada. E dessa maneira, o trauma da invasão de estímulos pode ser minimizado. É isso que ocorre quando o choque mecânico causa grave lesão física; nesse caso, a libido não se desestrutura, mas é organizada em torno da lesão, impedindo dessa maneira a ocorrência da neurose traumática. 


\section{SUSTO, ANGÚSTIA E PRONTIDÃO ANGUSTIADA}

A libido desestruturada, que explica a gênese da neurose traumática, nada mais é que a angústia. Para essa afirmação, tomamos as palavras de Monzani (1989):

"No caso de um acidente aconteceria o seguinte: o choque provocado geraria um grande susto e, simultaneamente, uma liberação excessiva de libido sexual. Essa libido, no entanto, permanece livre, flutuante, porque não tem ou não encontra um objeto específico no qual se apazigue. Ora, nesse caso, como sabemos, essa libido livre, flutuante, não encontrando um canal adequado de liberação, se 'desestrutura'(e se transforma em angústia). E essa angústia é a invasão pulsional na forma de um puro afeto, uma pura soma de excitação sem ligação que aparece como problemática para o aparelho psíquico, no caso dos acidentes graves sem lesão física." (MONZANI, 1989, p. 171, grifo nosso)

Em Além do princípio do prazer, Freud (1920/1980) estabelece que a angústia denota um estado de expectativa que se opõe ao susto (conforme já indicava a Conferência XXV [FREUD, 1917/1980]). O autor declara que, no momento do trauma, o aparelho psíquico é tomado de susto, o que significa que não houve angústia para assinalar a iminência do perigo e, dessa forma, incitar a defesa. E defesa, aqui, equivale à tomada de energia suficiente para a vinculação das excitações afluentes.

“E atribuímos ainda importância ao elemento de susto. Ele é causado pela falta de qualquer preparação para a angústia, inclusive a falta de hipercatexia dos sistemas que seriam os primeiros a receber o estímulo. Devido à sua baixa catexia, esses sistemas não se encontram em boa posição para vincular as quantidades afluentes de excitação, e as consequências da ruptura no escudo defensivo decorrem mais facilmente ainda. Ver-se-á, então, que a preparação para a angústia e a hipercatexia dos sistemas receptivos constitui a última linha de defesa do escudo contra estímulos." (FREUD, 1920/1980, p.47, grifo nosso)

Advertimos que onde se lê preparação para a angústia (Angstbereitschaft), preferimos traduzir por prontidão angustiada, que significa, segundo nossa hipótese, que algo se acrescenta à angústia. É uma espécie de tomada de posição do ego, a partir de uma quantidade já estabelecida. Ou seja, a angústia, enquanto estado de expectativa, é um afeto utilizado pelo ego. Mas essa utilização só é possível na medida que já há um protótipo da angústia, o qual seria referente à tensão sexual desligada.

Dessa maneira, achamos interessante a distinção entre angústia quantidade e angústia sensação. Essa última especifica que a angústia está submetida à função do ego. Talvez a hipótese dessa distinção se esclareça em Esboço de psicanálise 
(FREUD, 1939/1980), quando Freud já tem disponível o conceito de id: “O id desconhece a solicitude acerca da garantia de sobrevivência e desconhece igualmente a angústia, ou talvez fosse mais correto dizer que, embora ele possa gerar os elementos sensoriais da angústia, não pode utilizar-se deles”(FREUD, 1939/1980, p.227, grifo nosso). Lembramos que, desde as formulações sobre a neurose de angústia, Freud estabelece o lugar para um protótipo da angústia, que seria a angústia somática, e para a utilização psíquica desse afeto.

E é o papel da angústia, no processo defensivo, que é enfatizado em Além do princípio do prazer (FREUD, 1920/1980). Notamos que Laplanche (1998) vê na prontidão angustiada, descrita nessa obra de 1920, uma singularidade em relação às demais formulações freudianas sobre a angústia, em especial aquelas apresentadas em Inibições, sintomas e angústia (FREUD, 1926/1980). Para Laplanche, a prontidão angustiada tem o valor de uma espécie de paraexcitações, o que não se confunde nem com a angústia automática, nem com a angústia sinal, as quais são explicadas em 1926 (idem). Segundo esse autor, a prontidão angustiada apresenta-se numa relação muito mais direta com a proteção contra os estímulos. Ela parece incitar uma defesa mais primária e geral, que aquela desencadeada pelos processos de angústia descritos em Inibições, sintomas e angústia (idem).

Concordamos com a ideia de que a prontidão angustiada deve ser de uma ordem anterior à angústia sinal, descrita em 1926. Contudo, enfatizamos que ambas são formas de utilização de uma angústia quantidade já estabelecida. De acordo com nosso raciocínio, a prontidão angustiada é, conforme dissemos, uma tomada de posição, isto é, uma assunção da angústia pelo ego, que o deixa em estado de alerta. Dessa maneira, a angústia sinal (que é a liberação de dose moderada de angústia) já é consequência desse estado de alerta em que o ego se encontra. Em outras palavras, o ego só pode liberar doses moderadas de angústia, para sinalizar perigos, se ele já tiver se apropriado da angústia quantidade.

Esse papel da prontidão angustiada está na base da compulsão à repetição. Pois, antes dessa compulsão buscar a repetição de experiências de prazer ou desprazer, ela busca o desenvolvimento da angústia (Angstentwicklung, termo que pode ser entendido como 'incremento', ‘desdobramento da angústia’) ausente no momento do trauma. O desenvolvimento da angústia, até a prontidão angustiada, causa a tensão suficiente para que o aparelho psíquico possa sujeitar a excitação recebida passivamente. Na compulsão à repetição, o desenvolvimento da angústia sinaliza retroativamente o perigo. Adotando esse pensamento, Freud (1920/1980) refere-se aos sonhos apresentados nos quadros de neurose traumática: "Esses sonhos esforçam-se por dominar retrospectivamente o estímulo, desenvolvendo a angústia suja omissão constituiu causa a neurose traumática."(FREUD, 1920/1980, p.46, grifo do autor). 


\section{A ANGÚSTIA, SEGUNDO O NOVO ENFOQUE DO DUALISMO PULSIONAL}

O trabalho da ligação psíquica tem como principal objetivo a descarga das excitações. Além do princípio do prazer (FREUD, 1920/1980) enfatiza a tendência primeira de evacuação total da energia, pelo aparelho psíquico. Essa tendência já era observada em Projeto para uma psicologia científica (FREUD, 1895a[1950]/1980), quando era designada por 'tendência à inércia'. Mas o texto de 1920 vem dizer que a descarga total das excitações acontece com o intuito de retornar ao primordial estado dos organismos vivos, qual seja, o estado inorgânico. Com isso, o autor declara a principal atividade da pulsão: a repetição, que tem como objetivo o referido retorno.

"Parece, então, que a pulsão é um impulso, inerente à vida orgânica, a restaurar um estado anterior de coisas, impulso que a entidade viva foi obrigada a abandonar sob a pressão de forças perturbadoras externas, ou seja, é uma espécie de elasticidade orgânica, ou, para dizê-lo de outro modo, a expressão da inércia inerente à vida orgânica." (FREUD, 1920/1980, p.53-54, grifo do autor)

E o surgimento da pulsão Freud (1920/1980) descreve da seguinte maneira: a atuação de forças externas desconhecidas gerou, na matéria inanimada, tensão suficiente para originar propriedades vitais. A reação da matéria, então viva, é descarregar essa tensão e retornar ao estado inanimado.

A contínua influência das forças externas fez com que o caminho desse retorno fosse cada vez mais complexo e longo. E Freud (1920/1980) adverte que qualquer avanço nesse percurso contraria os interesses dessa pulsão. O organismo só deve alcançar a morte (ou seja, o estado inorgânico) após concluir todos os processos inscritos em sua história. Essa pulsão, que impele o organismo a retornar ao estado inanimado, é designada pulsão de morte. As pulsões que buscam impedir o avanço desmedido desse processo, o autor denomina “pulsões de vida”. Assim, embora Freud (idem) afirme uma oposição entre essas classes de pulsões, elas trabalham no mesmo sentido, ou seja, a morte. A diferença entre elas é que uma busca o estado inorgânico da forma mais rápida (podemos dizer, de uma maneira cega), e a outra busca a sustentação do organismo, até que sejam percorridas todas as etapas inscritas em sua estrutura.

“São as verdadeiras pulsões de vida. Operam contra o propósito das outras pulsões, que conduzem, em razão de sua função, à morte, e este fato indica que existe oposição entre eles e os outros [...]. É como se a vida do organismo se movimentasse num ritmo vacilante. Certo grupo de pulsões se precipita como que para atingir o objetivo final da vida tão rapidamente quanto possível, mas, quando determinada etapa no 
avanço foi alcançada, o outro grupo atira-se para trás até um certo ponto, a fim de efetuar nova saída e prolongar assim a jornada.” (FREUD, 1920/1980, p.58)

Continuando as observações sobre a pulsão de vida, notamos que seu papel é estabelecido a partir da sexualidade, que nunca deixa de estar nos focos do autor. Em Além do princípio do prazer, Freud (1920/1980) toma o funcionamento das células germinais, para empreender sua análise sobre os interesses da sexualidade. A maior parte dessas células não acompanha o organismo em sua morte. Essa parte se solta do organismo e, em condições favoráveis, segue o próprio desenvolvimento, enquanto deixa restos de sua organização, os quais passam a perpetuar suas características vitais. E as forças que impulsionam as células germinais nesse processo são realizadas pelas pulsões sexuais, que o autor passa a incluir no grupo das pulsões de vida.

Descrevendo algumas experiências com protistas (organismos elementares), Freud (1920/1980) consegue expressão para as referências biológicas de sua nova teoria pulsional. Tais experiências afirmam que a conjugação de células diferentes (porém da mesma espécie) trabalha a favor da conservação da vida (isto é, inibe os processos de degeneração celular). O mesmo efeito é produzido pelo influxo de novas quantidades de estímulos nas células. Ao passo que, se o organismo é isolado e submetido aos seus próprios excrementos, há uma dissolução das tensões químicas que coincide com a morte. Ou seja, a natureza do organismo, por si só, conduz ao estado de inércia. E essa tendência original à morte é que faria com que o desprazer fosse sentido a cada incremento da excitação.

Nisso Freud (1920/1980) apoia a distinção entre pulsão de vida e pulsão de morte. A primeira busca a união com células diferentes e o incremento do nível energético; a segunda tende ao isolamento e à descarga total das excitações. O princípio de constância surge como resultado desses interesses. E nesse sentido, também pode ser visto o tipo de compromisso que se faz no jogo e na fusão entre agressão e libido.

Esse raciocínio permite que Freud (1920/1980) avance em suas investigações sobre o princípio do prazer. Em 1920, tal princípio não só perde a prioridade para o processo de ligação. Ele também passa a ser interpretado conforme os vetores da pulsão de morte ou do princípio de constância. Isto é, o prazer pode ser identificado com a descarga total das excitações, ou com a estabilidade das mesmas. A esse respeito, Freud (idem) oferece a seguinte indicação:

"O princípio de prazer, então, é uma tendência que opera a serviço de uma função, cuja missão é libertar inteiramente o aparelho mental de excitações, conservar a quantidade de excitação constante nele, ou mantê-la tão baixa quanto possível. Ainda não podemos decidir com certeza em favor de nenhum desses enunciados, 
mas é claro que a função estaria assim relacionada com o esforço mais fundamental de toda substância viva: o retorno à aquiescência do mundo inorgânico.” (FREUD, 1920/1980, p.83, grifo nosso)

\section{A ANGÚSTIA COMO RESULTADO DA ATUAÇÃO DA PULSÃO DE MORTE}

Freud (1920/1980) supõe que os impulsos, que levam aos investimentos necessários para a sobrevivência do indivíduo e da espécie, estão desde o início presentes e associados à pulsão de morte. Mas cumpre notar que essa associação não se dá com tranquilidade. Podemos ver aqui algo similar ao choque entre energia livre e energia ligada, que Freud localiza na gênese da dor. Na fusão entre pulsão de vida e pulsão de morte, acontece um embate entre a força que busca anular qualquer excitação e a energia que atua produzindo vínculos e incrementando sua carga. O funcionamento concorrente dessas duas pulsões é bem notado por Green (1988):

"Propomos a hipótese de que a meta essencial das pulsões de vida é garantir uma função objetalizante [...]. Pelo contrário, a meta da pulsão de morte é realizar ao máximo uma função desobjetalizante através do desligamento. [...] Na maior parte do tempo, assistimos com efeito apenas ao funcionamento concorrente das atividades em relação aos dois grupos de pulsão." (GREEN, 1988, p.59-60, grifo do autor)

Seguindo as teses freudianas sobre a angústia somática, encontramos como resultado imediato do choque entre essas pulsões, uma forma primordial da angústia, qual seja, um substrato somático que é tomado pelo ego em sua função defensiva. Julgamos ser possível dizer que a apropriação disso, que denominamos ‘angústia quantidade', estaria na base mesma do processo de formação do ego, na medida que o estado de Angstbereitschaft seria condição para a função defensiva, que caracteriza essa instância psíquica.

Mas cumpre notar que a teoria, sobre a neurose de angústia (FREUD, 1894c[1950]/1980), entende que a tensão sexual desligada é efeito de uma limitação contingente do aparelho psíquico. Já a angústia, que supomos como resultado do choque entre pulsões de vida e de morte, acontece na própria constituição desse aparelho e é inerente ao seu funcionamento.

Recordamos que a passagem da angústia quantidade para a angústia sensação (especificamente, prontidão angustiada) exige algum trabalho psíquico. Ou seja, o ego só pode assumir a angústia (e assim posicionar-se em expectativa) se houver algum domínio (Bindung) sobre ela. Nesse caso, a afirmação de que a compulsão à repetição desenvolve a angústia ausente no momento do trauma (FREUD, 1920/1980) significa que essa compulsão tem por objetivo tal domínio da angústia quantidade. 


\section{CONCLUSÃO}

As consequências teóricas e clínicas, dessas hipóteses sobre a angústia, não são trabalhadas nos limites deste artigo. Entretanto algumas considerações, nesse sentido, merecem ser citadas. Entre elas a de que a angústia, concebida da maneira aqui apresentada, não se refere a um estado contingente, capaz de ser superado pelo funcionamento adequado do aparelho psíquico, porquanto ela estaria presente na própria constituição desse aparelho e seria inerente ao funcionamento pulsional.

Essa angústia primordial apontaria para os limites das ligações psíquicas (uma vez que ela é concebida como resultado da atuação incessante da pulsão de morte, cuja direção é o desligamento psíquico). Mas ao mesmo tempo, acreditamos que ela indica também a importância do domínio psíquico, especificamente, a importância do limiar psíquico pelo qual esse substrato somático passaria, quando tomado pelo ego. Ou seja, tal limiar estaria representado por aquilo que especificamos como a apropriação da angústia quantidade, pelo ego. Pois dessa maneira, o ego ficaria no estado de prontidão angustiada, o qual Freud (1920/1980) entende estar na base das defesas psíquicas e do funcionamento geral do aparelho psíquico.

E sobre esse limite das representações psíquicas e suas relações com a angústia, apenas como breve comentário, recordamos o que diz Freud (1937/1980, p.287), em Análise terminável e interminável. Nessa obra, ele afirma a anterioridade e a irredutibilidade da angústia de castração ao domínio psíquico (já tendo especificado [FREUD, 1926/198] que toda a angústia seria, em última instância, angústia de castração) e suas repercussões na transferência (D’AVILA LOURENÇO, 2005b). Interessante notar que Lacan (1962-1963), justamente nesse ponto, encontra o motor do processo analítico: a angústia, evidenciando o limite psíquico, seria o que possibilita a assunção da falta-a-ser. Assim, entendemos que, para esses autores, a angústia é um afeto arcaico, que se desdobra em diversas instâncias e movimenta o aparelho psíquico.

Sem a pretensão de abarcar toda a problemática que as concepções sobre a angústia e o funcionamento pulsional suscitam, no espaço deste artigo apenas concluímos que, conceber a angústia como resultado imediato do encontro entre pulsão de vida e pulsão de morte, bem como admitir o papel da prontidão angustiada para a capacidade do aparelho psíquico dominar as excitações, indica que esse afeto é o mais original e importante para a existência humana.

Recebido em 26/3/2007. Aprovado em 18/2/2008. 


\section{REFERÊNCIAS}

BREUER, J. \& FREUD, S. (1980) Edição standard brasileira das obras completas de Sigmund Freud, Rio de Janeiro: Imago Editora.

(1893 [1895]) “Estudos sobre a histeria”, v. II, p. 43-369.

CANEPPELE, A. (1996) "A angústia na formação da concepção freudiana de afeto”. Dissertação (Mestrado em Filosofia). Instituto de Filosofia, Universidade de São Paulo.

D’AVILA LOURENÇO, L. C. (2005a) A angústia, segundo Freud e Heidegger. Tese (Doutorado em Psicologia). Faculdade de Filosofia, Ciências e Letras de Ribeirão Preto, Universidade de São Paulo. (2005b) Transferência e complexo de Édipo, na obra de Freud: notas sobre os destinos da transferência. Psicologia: Reflexão e Crítica, ano 2005, n. 1. Porto Alegre: Universidade Federal do Rio Grande do Sul, p. 143-149.

FREUD, S. (1980) Edição standard brasileira das obras completas de Sigmund Freud, Rio de Janeiro: Imago Editora.

(1894a[1950]). “Rascunho E”, v. I, p. 211-217.

(1894b) "Sobre os critérios para destacar da neurastenia uma síndrome particular denominada 'neurose de angústia', v. III, p. 107-141. (1895a[1950]) "Projeto para uma psicologia científica", v. I, p. 303421.

(1895b[1950]) “Rascunho G”, v. I, p.2230228.

(1900) “A interpretação de sonhos”, v. IV, p.9-322.

(1915) “A repressão”, v. XIV, p.191-239.

(1917) “Conferência XXV”, v. XVI, p. 457-479.

(1920/1980) “Além do princípio do prazer”, v. XVIII, p. 17-89.

(1923/1980) “O ego e o id”, v. XIX, p.23-78.

(1926/1980) "Inibições, sintomas e ansiedade”, v. XX, p. 107-201.

(1937/1980) “Análise terminável e interminável”, v. XXIII, p. 239287.

(1939/1980) “Esboço de psicanálise”, v. XXIII, p. 165-331.

GREEN, A. (1988) "Pulsão de morte, narcisismo negativo, função desobjetalizante”, in GREEN, A. et al. (org.) A pulsão de morte, São Paulo: Escuta.

LACAN, J. (1962-1963) L’Angoisse. Seminaire X. Disponível em: http:// www.ecole-lacanienne.net (site da Ecole Lacanienne de Psychanalyse). Acesso em: 25/9/2003.

LAPLANCHE, J. (1998) “A angústia”, in Problemáticas I. São Paulo: Martins Fontes.

MONZANI, L. R. (1989) Freud: 0 movimento de um pensamento. Campinas: Editora da Unicamp.

Lara Cristina d'Avila Lourenço

laracdl@unifesp.br 